\title{
Adaptive population structure shifts in invasive parasitic mites, Varroa destructor
}

\author{
Arrigo Moro $^{1,2}$ | Tjeerd Blacquière ${ }^{3}$ | Bjørn Dahle ${ }^{4,5}$ | Vincent Dietemann ${ }^{2,6}$ |

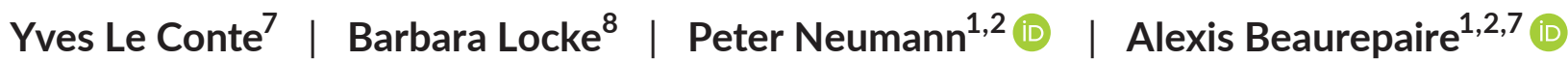

\footnotetext{
${ }^{1}$ Vetsuisse Faculty, Institute of Bee Health, University of Bern, Bern, Switzerland

${ }^{2}$ Swiss Bee Research Center, Agroscope, Bern, Switzerland

${ }^{3}$ Wageningen University \& Research, Wageningen, Netherlands

${ }^{4}$ Norwegian Beekeepers Association, Kløfta, Norway

${ }^{5}$ Faculty of Environmental Sciences and Natural Resource Management, Norwegian University of Life Sciences, Ås, Norway

${ }^{6}$ Department of Ecology and Evolution, University of Lausanne, Lausanne, Switzerland

${ }^{7}$ UR 406 Abeilles et Environnement, INRAE, Avignon, France

${ }^{8}$ Department of Ecology, Swedish University of Agricultural Sciences, Uppsala, Sweden

Correspondence

Alexis Beaurepaire, Vetsuisse Faculty/ University of Bern, Institute of Bee Health, Bern, Switzerland.

Email: Alexis.Beaurepaire@vetsuisse.unibe. ch

Funding information

The Persephone Charitable and

Environmental Trust; European Commission; Dutch Ministry of Agriculture, Nature and Food Quality; Ricola Foundation Nature and Culture; Vinetum Foundation
}

\begin{abstract}
Comparative studies of genetic diversity and population structure can shed light on the ecological and evolutionary factors governing host-parasite interactions. Even though invasive parasites are considered of major biological importance, little is known about their adaptative potential when infesting the new hosts. Here, the genetic diversification of Varroa destructor, a novel parasite of Apis mellifera originating from Asia, was investigated using population genetics to determine how the genetic structure of the parasite changed in distinct European populations of its new host. To do so, mites infesting two categories of hosts in four European regions were compared: (a) adapted hosts surviving through means of natural selection, thereby expected to impose strong selective pressure on the mites, and (b) treated host populations, surviving mite infestations because acaricides are applied, therefore characterized by a relaxed selection imposed by the host on the mites. Significant genetic divergence was found across regions, partially reflecting the invasion pattern of $V$. destructor throughout Europe and indicating local adaptation of the mite to the host populations. Additionally, varying degrees of genotypic changes were found between mites from adapted and treated colonies. Altogether, these results indicate that $\mathrm{V}$. destructor managed to overcome the genetic bottlenecks following its introduction in Europe and that host-mediated selection fostered changes in the genetic structure of this mite at diverse geographic scales. These findings highlight the potential of parasites to adapt to their local host populations and confirm that adaptations developed within coevolutionary dynamics are a major determinant of population genetic changes.
\end{abstract}

\section{KEYWORDS}

coevolution, genetic diversity, host-parasite interactions, invasive species, population genetics, population structure

This is an open access article under the terms of the Creative Commons Attribution License, which permits use, distribution and reproduction in any medium, provided the original work is properly cited.

(c) 2021 The Authors. Ecology and Evolution published by John Wiley \& Sons Ltd. 


\section{1 | INTRODUCTION}

Coevolution is a process of reciprocal evolutionary changes between interacting species (Ehrlich \& Raven, 1964; Thompson, 2005). Adaptations developed within host-parasite interactions strongly shape the genetics of the coevolving species (Anderson \& May, 1982; Thompson, 2005; Woolhouse et al., 2002). Notably, the rate of genetic changes is expected to be particularly swift in parasite populations compared to their hosts because of their shorter generation time (Paterson et al., 2010; Schmid-Hempel, 2011). Yet, the selection of specific parasite adaptations is not uniform for parasites infesting distinct populations of hosts, because different selective forces may act on these populations (Gandon \& Zandt, 1998). These forces, composed of diverse elements of environmental factors or unique host population adaptations, generally result in the genetic diversification of parasite populations at varying geographic scales, thereby generating geographic mosaics of coevolution (Thompson, 2005).

Although adaptations of parasites to their host traits have been studied extensively in silico (Gandon \& Michalakis, 2002) and in vitro (Brockhurst \& Koskella, 2013), evidences of mosaics of coevolution in invasive parasites infesting novel hosts remain scarce. The relatively recent coevolving system between the Western honey bee, Apis mellifera, and the obligate ectoparasitic mite, Varroa destructor, represents an ideal opportunity to investigate the impact of host adaptations on parasite evolution in real time (Dietemann et al., 2012; Oldroyd, 1999). Originally, V. destructor infested colonies of Eastern honey bees, Apis cerana, in Asia (Oldroyd, 1999; Rath, 1999). However, the introduction of A. mellifera colonies in the native range of the parasite resulted in the mite shifting host in the middle of the 20th century, and in its spread to almost all locations where beekeeping with the Western honey bee is practiced (Traynor et al., 2020). The spread of these parasites was particularly swift in Europe. Having been first detected in eastern regions of the continent in the beginning of the 1970s, it had dispersed throughout most of the continent just two decades later (Rosenkranz et al., 2010).

Out of the many $V$. destructor haplotypes found in A. cerana colonies (Navajas, 2010), only two are known to have switched to A. mellifera and to have emigrated from Asia (Anderson \& Trueman, 2000). In addition to this original bottleneck, and coupled with the incestuous mating behavior of the mite (Rosenkranz et al. 2010), the host shift and subsequent spread of the pest has resulted in a highly homogenous genetic population structure within the invasive populations of V. destructor (Solignac et al., 2005). Despite this low genetic diversity, $V$. destructor has flourished as an invasive parasite, with devastating consequences for its new host (Neumann \& Carreck, 2010; Potts, Biesmeijer, et al., 2010) and the quasi-eradication of wild honey bee populations in Europe (Jaffé et al., 2010; Moritz et al., 2007). In A. mellifera colonies, mite population growth is exponential (Martin, 1998) and, due to its ability to vector lethal honey bee viruses (Beaurepaire et al., 2020; Traynor et al., 2020), survival of susceptible colonies is dependent on annual mite control treatments implemented by beekeepers (Boecking \& Genersch, 2008; Le Conte et al., 2010).

These regular mite treatments may remove the selective pressure imposed by the parasite (May \& Anderson, 1990; SchmidHempel, 2011), thereby limiting the full potential of host adaptations (Fries \& Camazine, 2001; Neumann \& Blacquière, 2017) as well as the selection pressure of the host on $V$. destructor. Only occasionally were populations of European Western honey bees in France, Sweden, The Netherlands, and Norway left untreated and had the opportunity to adapt by means of natural selection (Fries et al., 2006; Kruitwagen et al., 2017; Le Conte et al., 2007; Locke, 2016; Oddie et al., 2017; Panziera et al., 2017). These adapted small honey bee populations, in France, The Netherlands, Norway, and Sweden, are considered resistant as they are surviving without the need for acaricide treatments by expressing a wide variety of traits that enable them to interfere with V. destructor population growth (Locke, 2016; Mondet et al. 2020).

Given that populations of V. destructor were genetically homogenous upon their introduction in Europe (Solignac et al., 2005), the adaptation potential of this invasive parasite has received little attention (Eliash \& Mikheyev, 2020). Yet, the reduced diversity and common origin of the recently introduced mites represents a perfect starting point to study how adaptation to novel host populations and different environments can induce genetic diversification in the parasite. More specifically, when coevolving with adapted A. mellifera colonies, mites would be expected to swiftly develop counteradaptations against the resistance traits of the hosts in order to survive. Such adaptations should result in changes in the levels of genetic diversity and population structure of the mites (Schulte et al., 2010, 2013). For instance, the length of brood production during the season, which is a trait known to enable honey bee survival to V. destructor (Locke, 2016), may influence the yearly number of mite reproductive cycles and the level of recombination of inbred mite lineages (Beaurepaire et al., 2017). In contrast, mites infesting susceptible colonies that require regular treatments may face different selective forces. In this case, treatments may relax the selective pressure of mite infestation on the hosts but are instead a strong selective pressure on the parasite population, which could also lead to the development of resistance toward treatments (GonzálezCabrera et al., 2018; Martin, 2004; Milani, 1999). Consequently, the genetic structure of $V$. destructor populations infesting honey bee colonies that are adapted to the mite versus those that are susceptible and require mite control for survival may follow different evolutionary paths and result in a geographic mosaic of coevolution (Thompson, 2005). To investigate this hypothesis, we performed an analysis of the genetic diversity and population structure of mites infesting five adapted and five treated honey bee populations located in four European regions. Our results show significant genetic diversification across $V$. destructor populations in the studied regions and host populations, thereby suggesting that mites have overcome the initial bottleneck of their introduction and are adapting to their local host populations as predicted by the geographic mosaic of coevolution theory (Thompson, 2005). 


\section{2 | MATERIALS AND METHODS}

\section{1 | Sampling}

In this study, adapted honey bee populations are defined as groups of colonies that have survived V. destructor infestations without the need for treatments for more than ten years, and do not require treatments to survive for extended periods. In contrast, the susceptible host populations are defined as treated since they require frequent treatments and/or management practice in order to survive mite infestations. Such treated populations generally show significantly lower expression levels of mite resistance traits compared to adapted ones (Mondet et al. 2020). In 2017, adult female V. destructor mites were sampled from 32 treated and 28 sympatric adapted $A$. mellifera colonies, in various locations across four different regions: France, Netherlands, Sweden, and Norway (Tables 1 and 2). Mite samples were initially divided into 11 groups (Table 1), reflecting the apiary location and type of colony they were infesting (i.e., adapted or treated).

The treatments of the treated colonies differed across the studied regions (Table 1). The adapted and treated colonies were located in the same apiary at two locations (Avignon, France; Lelystad, Netherlands). At all other locations, the distance between treated and surviving colonies ranged from 2.5 to $325 \mathrm{~km}$ (Table 2). The mites $(N=1,310)$ were collected on adult workers using standard methods (i.e., powdered sugar, Dietemann et al., 2013) during the summer of 2016 and 2017 and were immediately transferred into $95 \% \mathrm{EtOH}$ and stored at $-20^{\circ} \mathrm{C}$ until DNA extraction.

\subsection{DNA extraction and genotyping}

Established protocols were followed to isolate total mite DNA (Beaurepaire et al., 2017). In brief, mites were washed twice in
$\mathrm{ddH}_{2} \mathrm{O}$ to remove the $\mathrm{EtOH}$ and then individually distributed in 96-well plates filled with $100 \mu \mathrm{l}$ of Chelex $^{\mathrm{TM}}$ solution. Individual mites were then crushed with sterile pipette tips, $5 \mu \mathrm{l}$ of $10 \mathrm{mg} / \mathrm{ml}$ Proteinase $\mathrm{K}$ was added, and their DNA was extracted following Walsh et al. (2013).

Initially, 20 microsatellites (Beaurepaire et al., 2017; Cornman et al., 2010; Evans, 2000) were tested on 12 individual mites from each location ( $N=132$ ) to assess the genetic diversity and population structure of the $V$. destructor samples. PCRs were conducted as detailed in Beaurepaire et al. (2019). Seven of the tested markers were polymorphic over all regions and were thus chosen for genotyping all samples ( $N=1,310$, Table 3 ). Twenty-four mites were genotyped for each colony whenever the infestation level allowed to. PCR products were sent to Genoscreen (Lille, France) to run on a 3730XL sequencer (Applied Biosystems ${ }^{\circledR}$, Carlsbad, CA). All mites were genotyped using the Peak Scanner TM software v 1.0 (Applied Biosystems ${ }^{\circledR}$, Carlsbad, CA).

\section{3 | Microsatellite DNA analyses}

In total, 1,310 mites were individually genotyped at seven polymorphic loci (Table 1). Notably, the data from Sweden (165 mites) have already been published in Beaurepaire et al. (2019) and are used here to compare the amplitude of genetic changes across distinct mite groups. To verify the independence of the markers used, all locus pairs were tested for linkage disequilibrium using the software Fstat V 2.9.3 (Goudet, 1995).

To assess genetic differences between $V$. destructor infesting adapted versus susceptible $A$. mellifera populations in the different locations, the mites were initially grouped depending on apiary location and the type of host colonies they infested (i.e., adapted or treated; Table 1). To confirm this a priori sample clustering, the levels

TABLE 1 Sampling overview

\begin{tabular}{|c|c|c|c|c|c|}
\hline Region & Location (coordinates) & Group & Treatment & $N$ colonies & $N$ mites \\
\hline \multirow{2}{*}{ France } & Avignon (43⒌' $\left.56.1^{\prime \prime} \mathrm{N}, 4^{\circ} 52^{\prime} 37.7^{\prime \prime} \mathrm{E}\right)$ & Treated & Amitraz & 6 & 168 \\
\hline & Solérieux $\left(44^{\circ} 20^{\prime} 40^{\prime \prime} \mathrm{N}, 4^{\circ} 49^{\prime} 33.2^{\prime \prime} \mathrm{E}\right)$ & Treated & Amitraz & 8 & 90 \\
\hline \multirow[t]{2}{*}{ Netherlands } & Tiengemeten $\left(51^{\circ} 43^{\prime} 56^{\prime \prime} \mathrm{N}, 4^{\circ} 20^{\prime} 54^{\prime \prime} \mathrm{E}\right)$ & Adapted (2) & None & 6 & 195 \\
\hline & Lelystad $\left(52^{\circ} 32^{\prime} 09^{\prime \prime} \mathrm{N}, 5^{\circ} 32^{\prime} 21^{\prime \prime} \mathrm{E}\right)$ & Adapted (2) & None & 6 & 143 \\
\hline \multirow[t]{2}{*}{ Norway } & Sørumtangen $\left(60^{\circ} 03^{\prime} 12.6^{\prime \prime} \mathrm{N}, 11^{\circ} 05^{\prime} 26.8^{\prime \prime} \mathrm{E}\right)$ & Adapted (5) & None & 5 & 175 \\
\hline & Hilton $\left(60^{\circ} 04^{\prime} 12.1^{\prime \prime} \mathrm{N}, 11^{\circ} 07^{\prime} 13.3^{\prime \prime} \mathrm{E}\right)$ & Treated & Oxalic Acid & 4 & 107 \\
\hline \multirow[t]{2}{*}{ Sweden } & Gotland $\left(57^{\circ} 4^{\prime} 7.3^{\prime \prime} \mathrm{N}, 18^{\circ} 12^{\prime} 27.0^{\prime \prime} \mathrm{E}\right)$ & Adapted (3-4) & None & 5 & 53 \\
\hline & Gotland $\left(57^{\circ} 22^{\prime} 27.0^{\prime \prime} \mathrm{N} 18^{\circ} 40^{\prime} 24.3^{\prime \prime} \mathrm{E}\right)$ & Treated (4) & Oxalic Acid & 4 & 38 \\
\hline
\end{tabular}

Note: Region, location, and origin of experimental colonies, acaricide treatment occurrence and type, number of sampled hives, and number of mites genotyped are shown. Some of the mite groups listed are numbered to provide references to previous studies (1. Le Conte et al., 2007, 2. Panziera et al., 2017, 3. Locke, 2016, 4. Beaurepaire et al., 2019, and 5. Oddie et al., 2017). 


\begin{tabular}{|lllll|}
\hline Region & Location 1 & Location 2 & $\begin{array}{l}\text { Spatial distance } \\
(\mathbf{k m})\end{array}$ & $\begin{array}{l}\text { Genetic } \\
\text { distance }\left(D_{\text {est }}\right)\end{array}$ \\
\hline France & Avignon (Ad, 1) & Avignon (Tr) & 0.01 & $0.029^{* * *}$ \\
\hline $\begin{array}{l}\text { France } \\
\text { Netherlands }\end{array}$ & $\begin{array}{l}\text { Solérieux (Tr) } \\
\text { Tiengemeten } \\
\text { (Ad, 2) }\end{array}$ & Avignon (Tr) & 45 & $0.009^{* * *}$ \\
\hline Netherlands & Lelystad (Tr) & 100 & $0.103^{* * *}$ \\
\hline Norway & $\begin{array}{l}\text { Sørumtangen } \\
\text { (Ad, 5) }\end{array}$ & Lelystad (Tr) & 0.01 & $0.081^{* * *}$ \\
\hline Sweden & $\begin{array}{l}\text { Gotland (Ad, } \\
\text { 3-4) }\end{array}$ & Uppsala (Tr, 4) & 325 & $0.009^{* * *}$ \\
\hline Sweden & $\begin{array}{l}\text { Gotland (Ad, } \\
\text { Sweden }\end{array}$ & Gotland (Tr, 4) & 10 & $0.021^{* * *}$ \\
\hline Uppsala (Tr, 4) & Gotland (Tr, 4) & 325 & $0.028^{* * *}$ \\
\hline
\end{tabular}

TABLE 2 Sampled locations and distances between adapted and treated apiaries in each country

Note: A significant but low positive correlation was found between spatial and genetic distance (Mantel test, $R^{2}=0.1393 ; p=.001$ ). Codes between brackets indicate the mite groups (Ad: adapted, Tr: treated), and numbers provide references to previous studies (1. Le Conte et al., 2007, 2. Panziera et al., 2017, 3. Locke, 2016, 4. Beaurepaire et al., 2019, and 5. Oddie et al., 2017).

${ }^{* * *}$ Stands for highly significant $\mathrm{p}$-values $(p<0.001)$.

TABLE 3 General information on the microsatellite primers used for the analysis

\begin{tabular}{llllll} 
Name & Reference & $T_{\mathrm{A}}$ & Size & $N_{\mathrm{A}}$ & $H_{\mathrm{O}}$ \\
\hline VD307 & $\begin{array}{c}\text { Cornman } \\
\text { et al. (2010) }\end{array}$ & 60 & 162 & 2 & 0.059 \\
\hline Vj292 & Evans (2000) & 60 & 233 & 4 & 0.005 \\
Vj294 & & 58 & 170 & 4 & 0.027 \\
Vj295 & & 58 & 150 & 4 & 0.002 \\
\hline Vdes01 & Beaurepaire & 60 & 400 & 4 & 0.065 \\
Vdes02 & et al. (2017) & 60 & 296 & 2 & 0.041 \\
Vdes03 & & 60 & 303 & 2 & 0.043 \\
\hline
\end{tabular}

Note: The annealing temperature $\left(T_{A}\right)$ and average fragment size (Size, bp) of the primers as well as the number of alleles $\left(N_{\mathrm{A}}\right)$ and average heterozygosity $\left(H_{O}\right)$ scored during the analysis are listed.

of genetic variance across sampling regions and between host categories (i.e., treated versus adapted) were tested using an analysis of molecular variance (AMOVA, Excoffier \& Smouse, 1992) performed in R v. 3.5.1 (R Core Team, 2018) with the poppr package (Kamvar et al., 2014).

Genetic diversity estimates, including number of alleles $\left(N_{A}\right)$ and observed heterozygosity $\left(H_{\mathrm{O}}\right)$, were compared using Fstat v. 2.9.3 (Goudet, 1995). These results were statistically compared using Kruskal-Wallis tests using R v. 3.5.1 (R Core Team, 2018). In order to understand whether the lowest sample size used in this study (i.e., Gotland treated mites, $N=38$ ) was suitable to accurately represent the genetic diversity of the mite groups, rarefaction analyses were conducted using the ADZE software (Szpiech et al., 2008), using the allelic richness averages obtained across all markers in each mite group.

To test the allelic divergence of $V$. destructor across regions and between honey bee groups within locations, estimates of $D_{\text {est }}$
(Jost, 2008) and pairwise tests of population differentiation were obtained for each pair of location (i.e., grouping individuals from the different host populations in each location) and within location for each possible adapted versus treated comparison using the software GenAlex v. 6.5 (Peakall \& Smouse, 2012). The statistical significance of the pairwise population divergence indexes was obtained using Fstat v. 2.9.3 (Goudet, 1995) after 55,000 permutations, as this software allows to correct for multiple comparisons. Additionally, the level of genetic differentiation $\left(D_{\text {est }}\right)$ between mite groups treated with different acaricides was compared using a Student $t$ test. Finally, to investigate the relationships between the genetic distance obtained with $D_{\text {est }}$ and the spatial distance separating the mite groups (see Table 2), a Mantel test of correlation (Mantel, 1967) was performed with GenAlex v. 6.5. For mite groups that were present on the same apiary (i.e., Avignon, France, and Lelystad, The Netherlands), a distance of 10 meters was considered.

Finally, the diversity and the prevalence of mite genotypes infesting the different honey bee populations were compared. To do so, the distribution of multilocus genotypes (MLGs) in each mite group was computed using the $\mathrm{R}$ package poppr (Kamvar et al., 2014). Comparison of the diversity of MLGs across adapted and treated populations was done by estimating the $95 \%$ confidence intervals of Shannon (Shannon \& Weaver, 1949) and Simpson (Simpson, 1949) diversity indexes using 1,000 bootstraps. In parallel, the differences in the distribution of the most common MLGs between the adapted and treated host populations within each region were tested. To do so, only the mite genotypes with a frequency of at least $5 \%$ in the considered locations were compared using Fisher exact test conducted using contingency tables in R. As tests were conducted pairwise between the populations of any given region, the $p$-values obtained were corrected for multiple comparisons using Holm's method (Holm, 1979). In this analysis, all individuals 
with missing data were excluded from the dataset, resulting in a total of 863 individuals.

\section{3 | RESULTS}

No significant linkage disequilibrium between pairs of markers was detected after correction for multiple comparisons (all $p$ values $>$.05). The AMOVA confirmed our a priori grouping, indicating that sampling regions and host groups (i.e., treated versus adapted) were significantly $(p<.01)$ structuring $V$. destructor populations (i.e., responsible for $41.9 \%$ and $7.6 \%$ of the total genetic variance observed, respectively; Table 4).

Variable, but low levels of observed heterozygosity $\left(H_{\mathrm{o}}=0.002-0.065\right)$ and number of alleles (NA $\left.=2-4\right)$ were found across the seven markers over all samples (Table 3 ). For all mite groups, the rarefaction analyses showed that allelic richness only increased marginally after $\sim 40$ mites were analyzed (Figure 1). The comparison of allelic divergence of $V$. destructor populations in Europe revealed diverging patterns across the sampled regions. This analysis revealed very low allelic divergence between France and the Netherlands $\left(D_{\text {est }}=0.01, p<.001\right.$ ), while mites from Sweden were more markedly differentiated from mites of these two regions ( $D_{\text {est }}=0.12, p<.001$ ). Surprisingly, the genetic

TABLE 4 AMOVA results

\begin{tabular}{|lccc|}
\hline Variation & Sigma & $\%$ & $p$-Value \\
\hline Between Region & 1.185 & 41.89 & $* *$ \\
$\begin{array}{l}\text { Between Group within } \\
\text { Region }\end{array}$ & 0.187 & 6.62 & $* *$ \\
\hline Within groups & 1.456 & 51.48 & $* *$ \\
\hline
\end{tabular}

Note: Variations between hierarchical grouping levels are reported. Levels of significance are indicated with stars $\left({ }^{* *} p\right.$-value $\left.=.01\right)$. Only samples with less than $5 \%$ missing values $(N=863)$ were considered in this analysis. divergence levels between samples from these three locations and mites from Norway were thrice as high $\left(D_{\text {est }}=0.32-0.38, p<.001\right.$; Figure 2).

The comparison of genetic diversity across mite groups infesting the different host populations revealed that the mean number of alleles and the observed heterozygosity levels did not differ significantly between these groups (Kruskal-Wallis tests, $p>.05$; Figure 3). However, the levels of genetic differentiation between mites sampled from adapted and treated populations within each region resulted all significant, with diverse $D_{\text {est }}$ levels (Figure 2). Notably, the degree of genetic differentiation weakly but significantly correlated with the distance separating the groups (Mantel test, $R^{2}=0.14, p=.001$; Figure 4). However, looking more closely at the pairwise comparisons between mite infesting different host groups revealed that mite genetic differentiation is not clearly determined by geographic distance. For instance, the level of divergence between mites in the two treated French populations was very low $\left(D_{\text {est }}=0.01\right)$ and nonsignificant (Table 5$)$ despite the distance separating these two groups $(45 \mathrm{~km})$. In contrast, higher and significant differences $\left(D_{\text {est }}=0.029-0.048, p<.001\right)$ were found when these two groups were compared with the mites infesting the French adapted population, despite the fact that one of the treated host group was in the same apiary as the adapted honey bees. Also, the lowest level of divergence in the Netherlands occurred between the two adapted groups ( $D_{\text {est }}=0.013, p<.001$ ), in spite of the $\sim 100 \mathrm{~km}$ separating them. In parallel, the pairwise allelic comparisons revealed that mites from the adapted host population in France and from Tiengemeten in the Netherlands were not significantly genetically different $\left(D_{\text {est }}=0.002, p=.056\right.$, Table 5$)$, while mites infesting susceptible populations in these two regions were $\left(D_{\text {est }}=0.07-0.08\right.$; $p<.001$, Table 5). Moreover, the average level of population divergence found between mites treated with Amitraz and mites groups treated with oxalic acid (average $D_{\text {est }}=0.21, \pm 0.21 S D$ ) did not differ significantly from that obtained when mite groups treated with oxalic acid were compared with each other (average $D_{\text {est }}=0.27, \pm 0.14$ $S D, t$ test, $p=.63)$.
FIGURE 1 Rarefaction analysis. Mean allelic richness as a function of the standardized sample size calculated with ADZE (Szpiech et al., 2008) for all the mite groups analyzed. The red dash line indicates the threshold, identified by the rarefaction analysis, below which the sample size is considered insufficient to capture the genetic diversity of the groups

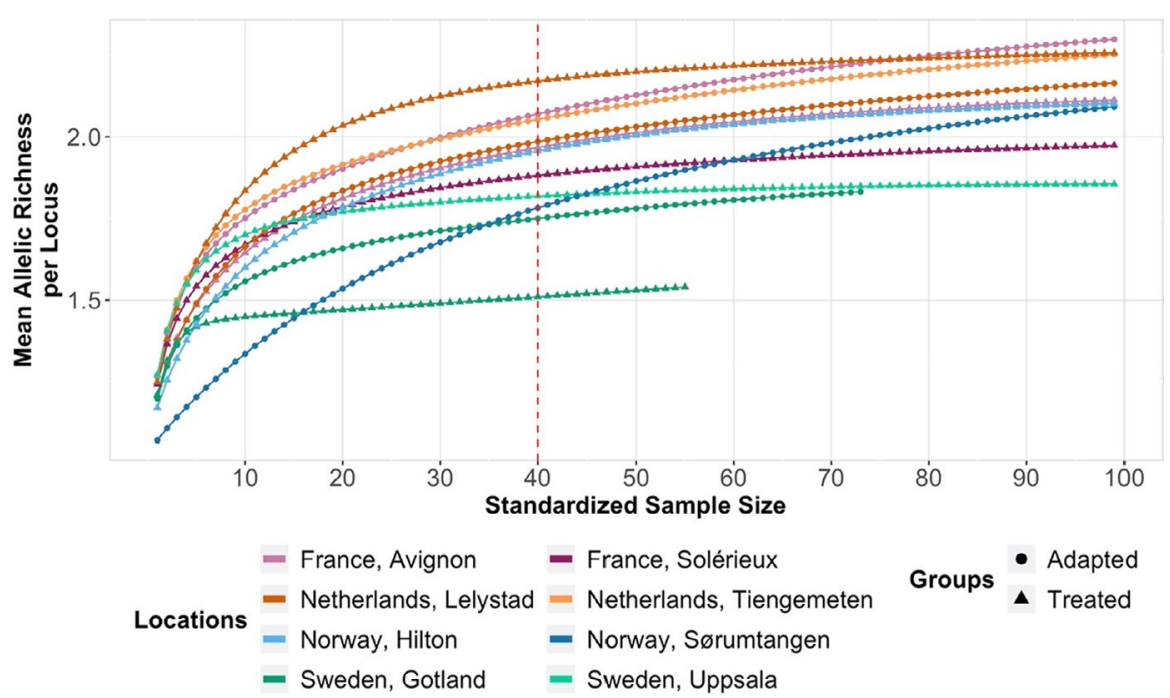



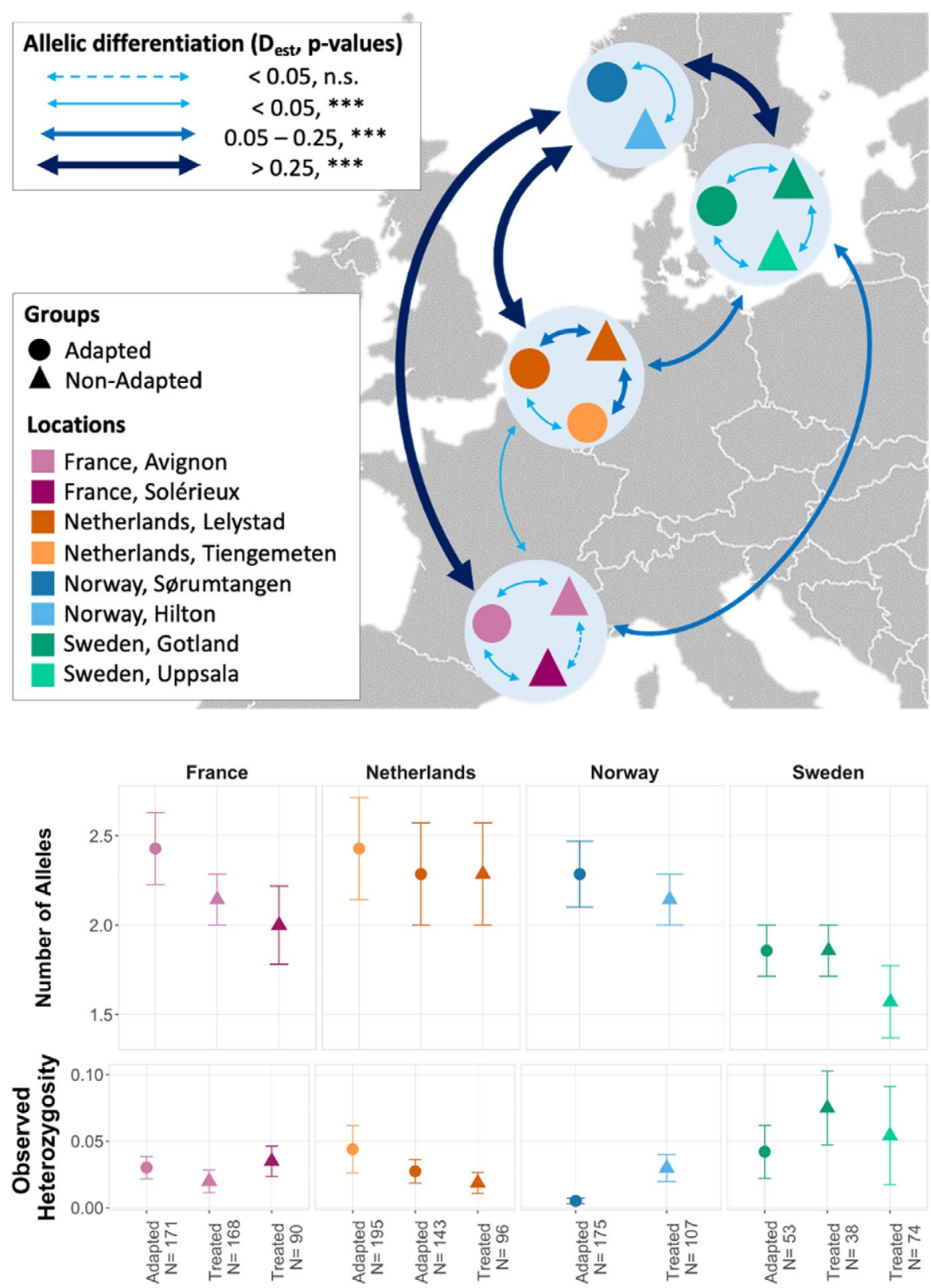

\section{Populations}

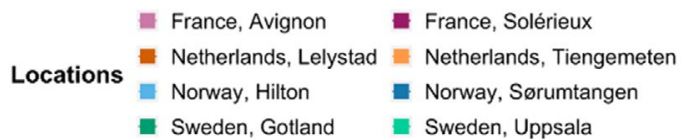

Groups

를 Norway, Hilton

Sweden, Uppsala
FIGURE 2 Varroa destructor population structure across locations and groups of colonies. Results of the tests of allelic divergence $\left(D_{\text {est }}\right)$ between mites infesting colonies of $A$. mellifera at the four locations and between treated and adapted colonies within each location. The thickness of the arrows linking populations shows the level of allelic divergence between them, from low $\left(D_{\text {est }}<0.05\right)$ to high $\left(D_{\text {est }}>0.25\right)$, while the dashed and solid lines represent statistical nonsignificance and significance, respectively ( ${ }^{* * *}$ indicates $p<.001)$. For every region, significant population structure divergences were found when adapted and treated mites were compared $(p<.001)$. Notably, Norwegian mites were genetically highly isolated from all the other mite groups $\left(D_{\text {est }}=0.32-0.38\right)$

FIGURE 3 Estimates of genetic diversity. Mean ( \pm standard error) number of alleles and observed heterozygosity for each group of mites. Mites were grouped by location (countries are distinguished by color and locations within countries by color shades) and by the type of colony they infested (designated by symbols). No significant difference was found when mite groups were compared across regions and between populations of the same region (Kruskal-Wallis test, $p>.05$ )
The analysis of multilocus genotypes (MLGs) showed 139 distinct mite genotypes over all groups (Table 6). A total of 36 genotypes were shared between the two host population (i.e., adapted and treated) and represented the majority of the samples (74.5\%). Additionally, 48 genotypes, representing $11.1 \%$ of the total number of mites included in the MLG analysis, were only found in adapted colonies across all locations, while 55 (14.4\%) were found only in treated populations. Several private MLGs (i.e., MLGs found only in one group) were detected in every group. Their numbers $(N=3-13)$ varied between groups, but only represented a minor proportion of the sampled mites $(0.5 \%-4.1 \%$, Table 6$)$.
Overall, contrasting patterns of MLG diversity could be observed when comparing mites from adapted and treated populations across the different locations (Figure 5). Notably, in France, significantly higher levels of the Shannon index $(\mathrm{H})$ were found in mites infesting the adapted host population $(95 \% \mathrm{Cl}=2.9-3.3)$ compared to the two mite groups sampled from the treated populations of the same region (95\% Cl $=2.0-2.5$ and 2.4-2.8). The same pattern was found in one adapted population of the Netherlands $(95 \% \mathrm{Cl}=3.1-3.5)$ when compared to the adapted $(95 \% \mathrm{Cl}=2.4-2.8)$ and treated populations (95\% $\mathrm{Cl}=2.4-2.9)$ from the same region. In addition, the distribution of the dominant MLGs varied significantly between adapted 


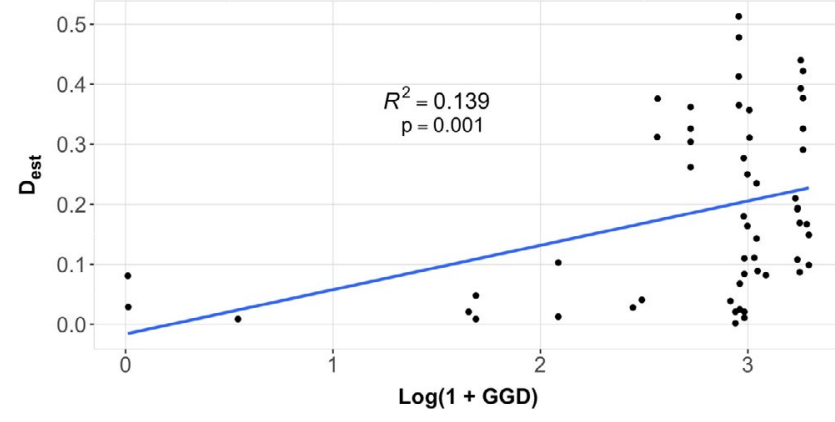

FIGURE 4 Correlation between geographic distance (GGD) and genetic distance $\left(D_{\text {est }}\right)$. Results of the Mantel analysis of the spatial and genetic distance separating the mite groups. A weak but significant correlation ( $p=.001$ ) was found between the distances

and treated colonies in each location (Fisher exact tests corrected for multiple testing, $p<.05$, Figure 6 ).

\section{4 | DISCUSSION}

Our results suggest that the genetic structure of European V. destructor is shaped by their interactions with their local host populations. These findings reveal that sympatric and allopatric mite populations are experiencing significant levels of genetic divergence that are probably caused by both unique host population traits and environmental differences across locations.

A weak and significant interaction $\left(R^{2}=0.14, p=.001\right)$ was found between the genetic and geographic distance separating the mite groups, indicating that geographic isolation can explain a small part of the genetic differences found between distant mite populations. Additionally, the pattern of genetic differentiation documented here appears to be further explained by the invasion history of the parasite in Europe. Historical reports of this invasion showed that V. destructor arrived in Europe through two routes. First, the mite is believed to have been introduced in 1971-72 in Eastern European countries and to slowly spread to the Northern regions of the continent, including Sweden (Griffiths \& Bowman, 1981; Rosenkranz et al., 2010). Secondly, the parasite was introduced in Germany in 1977, a source from which mites from France and Netherlands derived (Nixon, 1983; Potts, Roberts, et al., 2010; Ruttner \& Ritter, 1980). After its introduction in Europe, the trading of honey bee colonies between regions became restricted and subjected to strict regulations (European Commission, 1992), so to limit the spread of the parasite across countries. Our results match these previous reports of introduction as the low genetic differentiation between mites infesting French and Dutch honey bees suggests that these populations derived from a common origin, while more elevated levels of differentiation between these two locations and Sweden suggest a distinct introduction. However, the level of differentiation between mites from these three regions compared to Norwegian mites was much higher, pointing to a third introduction event. This hypothesis matches reports on the arrival of $V$. destructor in Norway, which was first found in the spring of 1993 in Oslo, while the natural spread of the mite was still confined to the southernmost part of Sweden. $V$. destructor was in fact found for the first time in Sweden on the island of Gotland in 1987 (Fries, 1987) and later in Malmö, on the southern Swedish mainland, in the spring of 1991 (Fries, 1991). Notably, the first identification of $V$. destructor infesting colonies along the Norwegian-Swedish border was reported in 1995, two years after the arrival of the mite in Norway, and was considered to be caused by a natural spread of the parasites from Norwegian apiaries. To date, the precise origin of the mites infesting Norwegian honey bee colonies remains to be identified. Nevertheless, this is the first report of a previously unknown route of introduction of $V$. destructor into Europe. Notably, the marked differentiation of these mites from all the other groups analyzed here may suggest that the Norwegian V. destructor originate from a different source population.

Over all the V. destructor populations sampled, relatively low numbers of alleles and heterozygosity levels were detected. However, the number of alleles detected appears to be higher than initially reported by other authors investigating the genetic diversity of $\mathrm{V}$. destructor infesting several European honey bee populations with microsatellites (Solignac et al., 2005). When genotyping 92 mites from Avignon with 13 polymorphic markers over a decade ago, these authors obtained a total of 1.3 alleles per marker. In the present study, taking place some 15 years later, 171 and 168 mites were sampled in two honey bee groups from Avignon, yielding more alleles per markers (i.e., an average of 2.4 and 2.1 alleles per marker). This temporal increase does not seem to be caused by the different sample sizes used between the two studies, as the rarefaction analysis showed that a sample size of 40 mites is enough to accurately quantify the diversity of invasive populations of $V$. destructor. Additionally, the analyses performed in the current study further suggest that $V$. destructor populations have diversified since their introduction in Europe, as shown by the high differences between and within locations from the same countries. When comparing the distribution of mite genotypes, a relatively high number of MLGs ( $N=139$ MLGs out of 1,310 mites genotyped) were found across the honey bee populations, including many rare MLGs private to specific regions and populations. Notably, the distribution of MLGs significantly differed across the populations studied, and strong and significant differences were also found when performing pairwise allelic differentiation analyses between regions. Altogether, these results suggest that the mites are adapting to their local host populations, despite the relatively recent genetic bottlenecks caused by both the host shift and introduction of the mite in Europe (Solignac et al. 2005).

In addition to the diversification of V. destructor across Europe, the comparison between mites infesting sympatric adapted and treated host colonies revealed intriguing patterns of genetic structure. Although the specific mechanisms of horizontal large-scale transmission of the parasite currently remain unknown, the mite can easily spread within and between apiaries of a given region (Frey et al., 2011; Fries \& Camazine, 2001). In molecular terms, this high transmission may prevent genetic isolation of mites infesting honey bee colonies within and across apiaries (Beaurepaire et al., 2015, 
TABLE 5 Pairwise population divergence indexes $\left(D_{\text {est }}\right)$

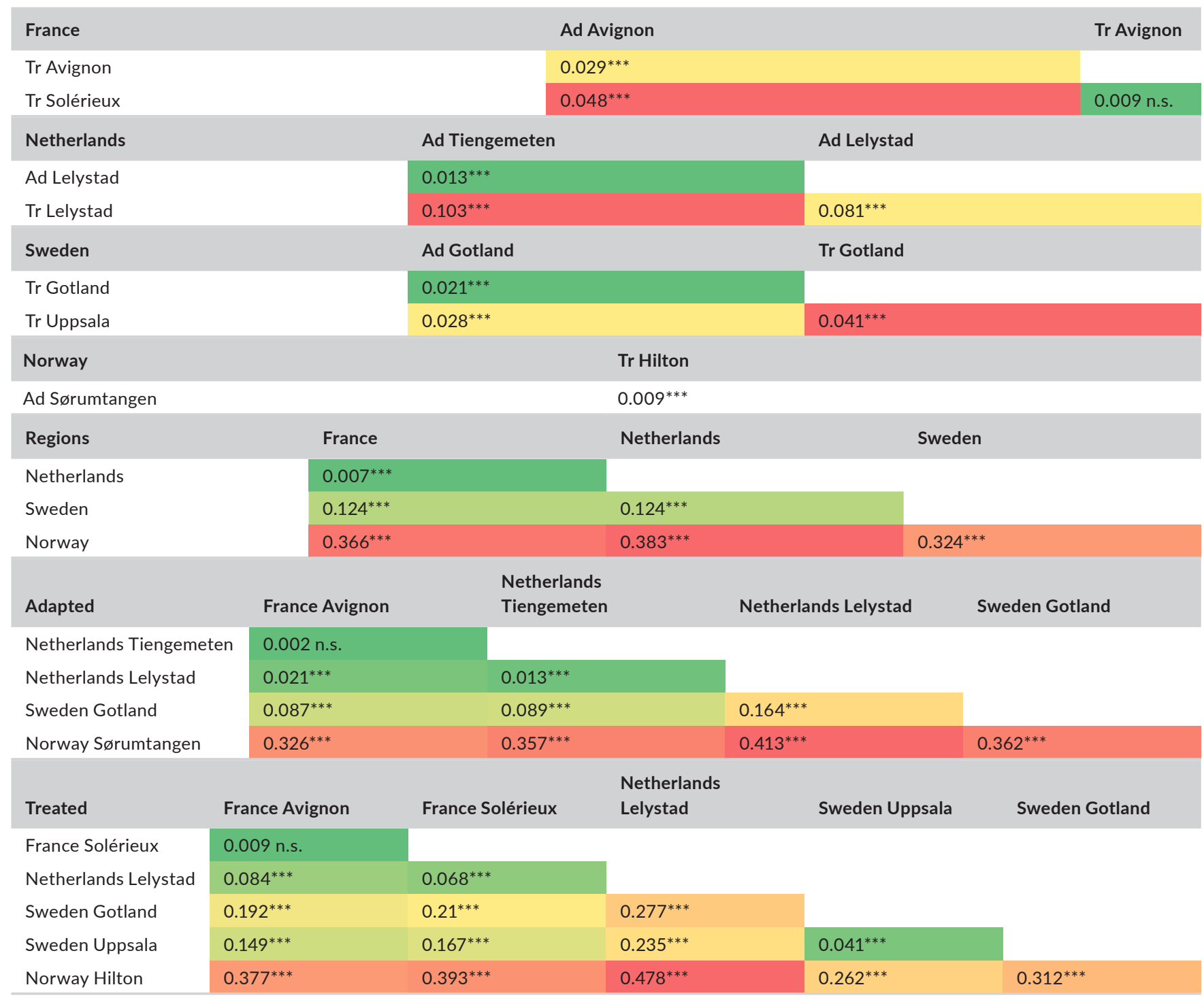

Note: Results of pairwise population differentiation indices across countries when pooling all mites of a given region (overall), comparing treated colonies (Tr), and comparing adapted colonies (Ad). Numbers indicate $D_{\text {est }}$ value, and stars and "n.s." indicate $p$-value of the test (***: $p<.001$, n.s.: nonsignificant). Values are color-coded according to the degree of $D_{\text {est }}$ (red $=$ high, yellow $=$ moderate, and green $=$ low).

2017; Dynes et al., 2017). Despite this, we here observed significantly different allelic patterns and MLG distribution between V. destructor samples infesting adapted and treated honey bee colonies in all the four regions studied. These differences may be explained by numerous factors. First, neutral processes such as genetic drift may cause isolated mite populations to diverge (Freeland et al., 2011). However, the differences reported here do not seem to result entirely from this factor as the patterns of genetic differentiation have been found to be consistently dependent on mite-host association in every location (Figures 2 and 5). Although a weak isolation by distance at the continental scale was found, the patterns of genotypic differences between $V$. destructor infesting adapted and treated populations did not vary according to the distance separating the groups in a given region. For example, differences remained significant even in locations where the two host populations were located at the very same apiary (i.e., Lelystad, the Netherlands, and Avignon, France).

Second, acaricide treatments of the susceptible colonies could have affected the population structure of the mites. The application of pesticides is known to lead to the development of resistance in pest populations (Georghiou, 1972), V. destructor being no exception (Martin, 2004; Milani, 1999; Spreafico et al., 2001). Although we here did not test directly for the presence of acaricide resistance, the variability of microsatellites markers in response to pesticidedriven population genetic changes can provide indirect evidence for changes in genotypic diversity and structure caused by pesticides (de Meeûs et al., 2007; Osakabe et al., 2009; Pascual-Ruiz et al., 2014). Notably, the use of acaricides should reduce population sizes and diversity levels. As a consequence, an increase of the level of genetic divergence between treated and nontreated populations may also 
TAB LE 6 Comparison of the mite multilocus genotypes

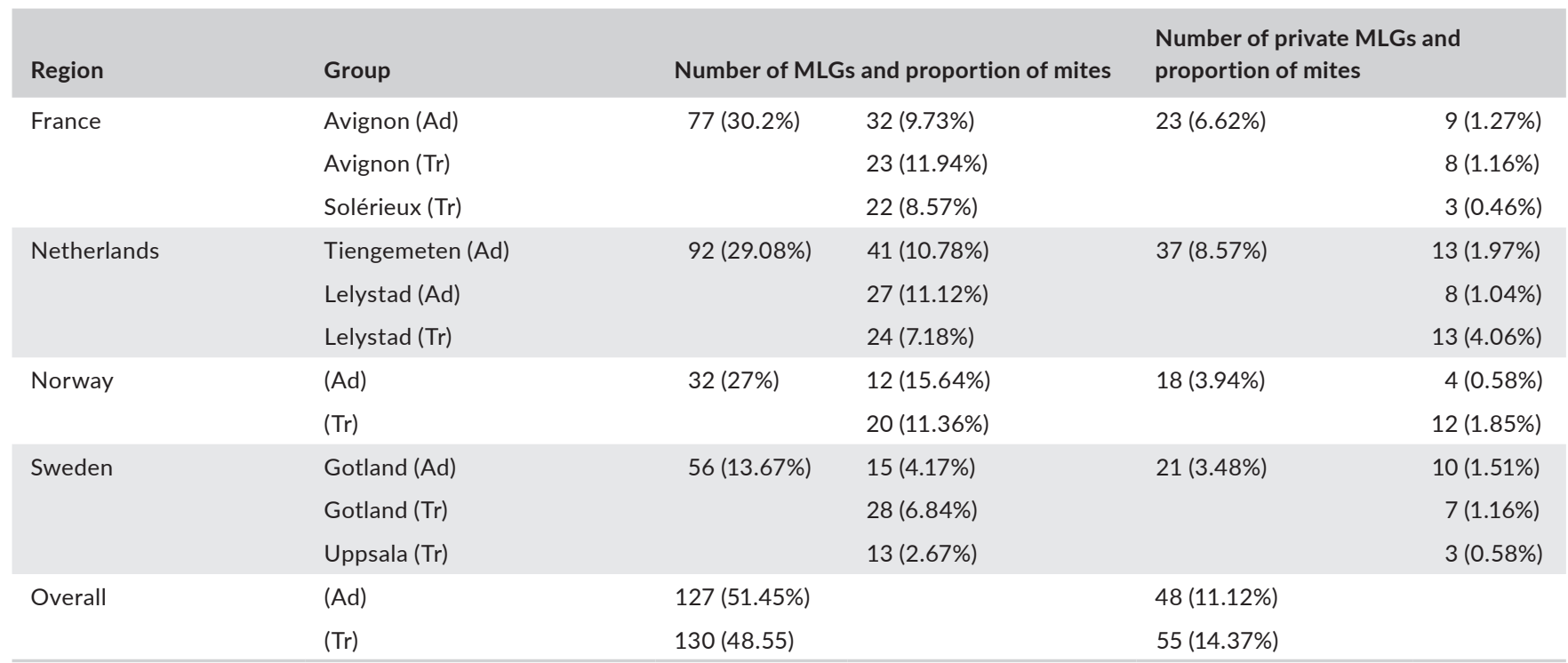

Note: The number and proportion of mite multilocus genotypes (MLGs) across the locations and groups of honey bee colonies are shown. The number of private MLGs exclusive to each group of mites is also reported. The codes between brackets indicate the mite groups (Ad: adapted, Tr: treated), and numbers provide references to previous studies (1. Le Conte et al., 2007, 2. Panziera et al., 2017, 3. Locke, 2016, 4. Beaurepaire et al., 2019, and 5. Oddie et al., 2017), while the percentages represent the proportion of individuals out of the 863 mites included in this analysis.

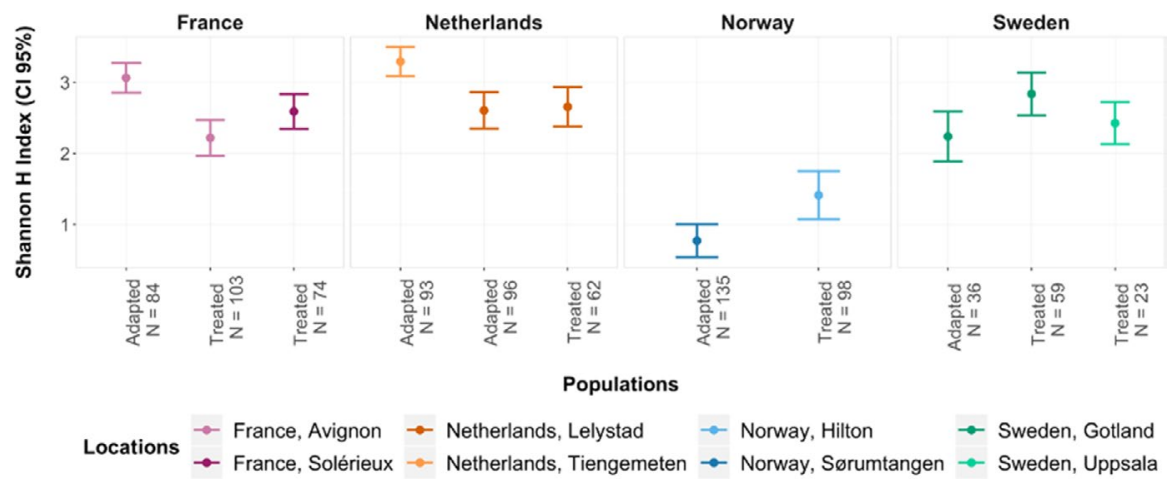

FIGURE 5 Comparison of MLG diversity (Shannon Index). Graph representing 95\% confidence interval of the Shannon index, illustrating the diversity of multilocus genotypes (MLGs) across mite groups. The diversity analysis was conducted after excluding all mites with missing data. The sample size after this exclusion is reported for every group. Overall, contrasting patterns of MLG diversity could be observed between adapted and treated populations across the different locations. Significantly higher levels of MLG diversity were found in mites infesting adapted host populations in Avignon (France) and Tiengemeten (the Netherlands) compared to the mite infesting treated hosts from their respective region. Notably, for Norwegian mites, a significantly lower level of MLG diversity was found in the adapted group compared to treated one, whereas for Swedish mites, no significant difference was found

occur (Osakabe et al., 2009; Uesugi et al., 2009). Here, the number of alleles and the levels of heterozygosity did not differ significantly between mites from adapted and treated colonies, but the diversity of mite MLGs and/or the amplitude of genetic divergence varied between these groups across populations. Notably, three of the four treated populations examined in this study (Netherlands, Sweden, and Norway) have been regularly treated with oxalic acid to control V. destructor infestations. This organic acaricide has high and consistent efficacy (Gregorc \& Planinc, 2001) and works through contact by killing mites by means of high acidity (Nanetti, 1999). Given this very general mode of action, oxalic acid is not expected to select for any particular lineage of mites, as it has been demonstrated in a previous study, where even after a repeated and prolonged exposure to this compound, mites remained susceptible (Maggi et al., 2017). In contrast, the synthetic acaricide (i.e., Amitraz) used to treat the susceptible colonies in Avignon and Solérieux can foster the development of resistance in V. destructor (Kamler et al., 2016) and could have caused some of the genetic differences between mites from adapted and treated host populations in France. However, the number of alleles and level of heterozygosity of mites infesting treated hosts in France was as low as in the other mite groups. Moreover, the average level of population divergence obtained in mites treated with Amitraz versus oxalic acid and in populations treated with oxalic acid only did not differ significantly. Altogether, these findings suggest that the acaricide treatments of the susceptible colonies did not greatly affect the genetic diversity and population structure of V. destructor. 


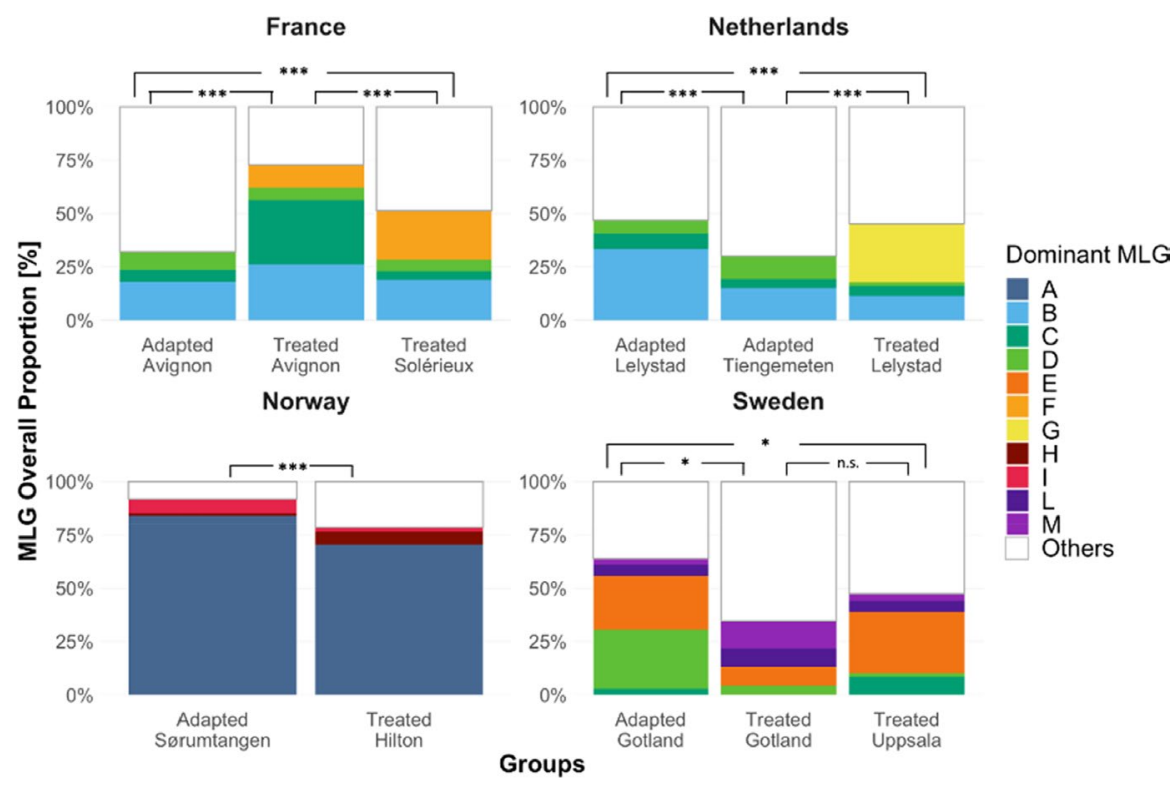

FIGURE 6 Distribution of the dominant mite genotypes. Frequency of the dominant mite multilocus genotypes (MLGs) at each location for adapted and treated A. mellifera colonies. Dominant MLGs are defined by a frequency $>5 \%$ at the given location and are represented by different colors. The less frequent MLGs were pooled and designated as "Others." Mites with missing data were excluded from this analysis. The stars indicate the significance level of $p$-values obtained using Fisher exact test calculated with contingency table coupled with Holm's correction for multiple comparison $\left({ }^{*} p<.05,{ }^{* * *} p<.001\right)$, while n.s. indicates nonsignificance. The distribution of mite genotypes varied significantly when adapted and treated mite groups were compared in every region (Holm's adjusted $p<.05$ )

Another factor that may explain the results documented here lies in the natural adaptations of honey bee colonies to V. destructor. Most strikingly, the pairwise comparisons revealed that mites from adapted colonies from France and one location of the Netherlands (Tiengemeten) were not significantly genetically different, while the mite infesting susceptible colonies in these two regions were. This may suggest parallel evolution similar to their honey bee hosts (Locke et al., 2012; Oddie et al., 2018). On the other hand, the patterns of change in the diversity of MLGs between mites infesting the adapted and treated host populations were not consistent across regions. For instance, in the populations located in France and the Netherlands, a higher diversity of MLGs was observed in the adapted colonies compared to local treated ones. In contrast, the level of MLG diversity was higher in the treated colonies from Norway and was not significantly different between the three groups located in Sweden. Possibly, in some surviving populations, host-mediated selection may promote mite genotypes expressing a decreased level of reproduction (i.e., selection for lower parasite virulence; Seeley, 2007), while in others, the hosts may select for mite genotypes having specific chemical mimicry abilities (Kather et al., 2015; Le Conte et al., 2015). These results suggest that different selective forces may be acting on the various mite groups, thereby representing hot spots and cold spots of evolution as postulated by the geographic mosaic of coevolution theory (Thompson, 2005). Although the particular host traits shaping the population structure of $V$. destructor remain to be discovered, these results confirm previous findings documenting significant temporal changes of population structure between parasites sampled in adapted and susceptible honey bee colonies over nine years
(Beaurepaire et al., 2019). Altogether, these results provide empirical evidence that honey bee selective pressure influences $V$. destructor population structure, as previously observed in other systems (birds-fleas: Alves et al., 2019; donkeys-helminths: Decaestecker et al., 2007; kangaroos-worms: Koskella \& Lively, 2009).

In conclusion, the data presented here show that the genetic structure of $V$. destructor populations differs across European regions and across sympatric groups of varroa mite-adapted and treated hosts, resulting in a geographic mosaic of coevolution between the ectoparasitic mites and their hosts in different populations throughout Europe. These findings shed new light into the interactions between $V$. destructor and $A$. mellifera, and highlight the so far underestimated role of the mite adaptations in this system (Eliash \& Mikheyev, 2020). Half a century after its introduction into Europe, the ongoing genetic diversification of $V$. destructor in Europe illustrates well the evolutionary potential of parasites and represents a prominent example of ongoing coevolution between hosts and parasites.

\section{ACKNOWLEDGMENTS}

The authors of this work wish to express their sincere gratitude to COLOSS for providing the platform for the conception and realization of this project and to the beekeepers maintaining the experimental colonies. This study was financially supported by the Ricola Foundation Nature and Culture, the Vinetum Foundation, and The Persephone Charitable and Environmental Trust. TB acknowledges the Dutch Ministry of Agriculture, Nature and Food Quality and the European Commission for financial support (Projects NL 05/2.2; NL 08/2.1; NP 11/2.1; NP 14-6.1; NP 17.1). 


\section{CONFLICT OF INTEREST}

The authors declare no conflict of interest.

\section{AUTHOR CONTRIBUTIONS}

Arrigo Moro: Data curation (lead); Formal analysis (lead); Visualization (lead); Writing-original draft (lead); Writing-review \& editing (lead). Tjeerd Blacquière: Conceptualization (equal); Data curation (supporting); Methodology (equal); Validation (supporting); Writing-original draft (supporting); Writing-review \& editing (supporting). Bjorn Dahle: Conceptualization (equal); Data curation (supporting); Methodology (equal); Validation (supporting); Writing-original draft (supporting); Writing-review \& editing (supporting). Vincent Dietemann: Conceptualization (supporting); Investigation (supporting); Methodology (supporting); Writingoriginal draft (supporting); Writing-review \& editing (supporting). Yves Le Conte: Conceptualization (equal); Investigation (supporting); Methodology (equal); Validation (supporting); Writing-original draft (supporting); Writing-review \& editing (supporting). Locke Barbara : Conceptualization (equal); Data curation (supporting); Methodology (equal); Validation (supporting); Writing-original draft (supporting); Writing-review \& editing (supporting). Peter Neumann: Conceptualization (equal); Funding acquisition (lead); Methodology (equal); Project administration (equal); Resources (lead); Writingoriginal draft (supporting); Writing-review \& editing (supporting). Alexis Beaurepaire: Conceptualization (lead); Data curation (equal); Formal analysis (supporting); Methodology (lead); Project administration (supporting); Supervision (lead); Validation (lead); Writingoriginal draft (lead); Writing-review \& editing (lead).

\section{DATA AVAILABILITY STATEMENT}

The dataset used in this study can be found here: https://datadryad. org/stash/share/e_WmWloADcFQjut8RpxoVZ2StvUVdfL30hts2 bd7PFA.

\section{ORCID}

Peter Neumann (iD https://orcid.org/0000-0001-5163-5215 Alexis Beaurepaire iD https://orcid.org/0000-0002-9832-5609

\section{REFERENCES}

Alves, J. M., Carneiro, M., Cheng, J. Y., Lemos de Matos, A., Rahman, M. M., Loog, L., Campos, P. F., Wales, N., Eriksson, A., Manica, A., Strive, T., Graham, S. C., Afonso, S., Bell, D. J., Belmont, L., Day, J. P., Fuller, S. J., Marchandeau, S., Palmer, W. J., ... Jiggins, F. M. (2019). Parallel adaptation of rabbit populations to myxoma virus. Science, 363(6433), 1319-1326. https://doi.org/10.1126/science.aau7285

Anderson, D. L., \& Trueman, J. W. M. (2000). Varroa jacobsoni (Acari: Varroidae) is more than one species. Experimental \& Applied Acarology, 24(3), 165-189.

Anderson, R. M., \& May, R. M. (1982). Coevolution of hosts and parasites. Parasitology, 85(2), 411-426. https://doi.org/10.1017/S003118200 0055360

Beaurepaire, A. L., Krieger, K. J., \& Moritz, R. F. A. (2017). Seasonal cycle of inbreeding and recombination of the parasitic mite Varroa destructor in honeybee colonies and its implications for the selection of acaricide resistance. Infection, Genetics and Evolution, 50, 49-54. https:// doi.org/10.1016/j.meegid.2017.02.011
Beaurepaire, A. L., Moro, A., Mondet, F., Le Conte, Y., Neumann, P., \& Locke, B. (2019). Population genetics of ectoparasitic mites suggest arms race with honeybee hosts. Scientific Reports, 9(1), 11355. https://doi.org/10.1038/s41598-019-47801-5

Beaurepaire, A., Piot, N., Doublet, V., Antunez, K., Campbell, E., Chantawannakul, P., Chejanovsky, N., Gajda, A., Heerman, M., Panziera, D., Smagghe, G., Yañez, O., de Miranda, J. R., \& Dalmon, A. (2020). Diversity and global distribution of viruses of the western honey bee Apis mellifera. Insects, 11(4), 239. https://doi.org/10.3390/ insects11040239

Beaurepaire, A. L., Truong, T. A., Fajardo, A. C., Dinh, T. Q., Cervancia, C., \& Moritz, R. F. A. (2015). Host specificity in the honeybee parasitic mite, Varroa spp. in Apis mellifera and Apis cerana. PLoS One, 10(8), e0135103. https://doi.org/10.1371/journal.pone.0135103

Boecking, O., \& Genersch, E. (2008). Varroosis - the ongoing crisis in bee keeping. Journal Für Verbraucherschutz Und Lebensmittelsicherheit, 3(2), 221-228. https://doi.org/10.1007/s00003-008-0331-y

Brockhurst, M. A., \& Koskella, B. (2013). Experimental coevolution of species interactions. Trends in Ecology \& Evolution, 28(6), 367-375. https://doi.org/10.1016/j.tree.2013.02.009

Cornman, R. S., Schatz, M. C., Johnston, J. S., Chen, Y.-P., Pettis, J., Hunt, G., Bourgeois, L., Elsik, C., Anderson, D., Grozinger, C. M., \& Evans, J. D. (2010). Genomic survey of the ectoparasitic mite Varroa destructor, a major pest of the honey bee Apis mellifera. BMC Genomics, 11(1), 602. https://doi.org/10.1186/1471-2164-11-602

de Meeûs, T., McCoy, K. D., Prugnolle, F., Chevillon, C., Durand, P., Hurtrez-Boussès, S., \& Renaud, F. (2007). Population genetics and molecular epidemiology or how to "débusquer la bête". Infection, Genetics and Evolution, 7(2), 308-332. https://doi.org/10.1016/j. meegid.2006.07.003

Decaestecker, E., Gaba, S., Raeymaekers, J. A. M., Stoks, R., Van Kerckhoven, L., Ebert, D., \& De Meester, L. (2007). Host-parasite 'Red Queen' dynamics archived in pond sediment. Nature, 450(7171), 870-873. https://doi.org/10.1038/nature06291

Dietemann, V., Nazzi, F., Martin, S. J., Anderson, D. L., Locke, B., Delaplane, K. S., Wauquiez, Q., Tannahill, C., Frey, E., Ziegelmann, B., Rosenkranz, P., \& Ellis, J. D. (2013). Standard methods for varroa research. Journal of Apicultural Research, 52(1), 1-54. https://doi. org/10.3896/IBRA.1.52.1.09

Dietemann, V., Pflugfelder, J., Anderson, D., Charrière, J.-D., Chejanovsky, N., Dainat, B., de Miranda, J., Delaplane, K., Dillier, F.-X., Fuch, S., Gallmann, P., Gauthier, L., Imdorf, A., Koeniger, N., Kralj, J., Meikle, W., Pettis, J., Rosenkranz, P., Sammataro, D., ... Neumann, P. (2012). Varroa destructor: Research avenues towards sustainable control. Journal of Apicultural Research, 51(1), 125-132. https://doi.org/10.3896/IBRA.1.51.1.15

Dynes, T. L., De Roode, J. C., Lyons, J. I., Berry, J. A., Delaplane, K. S., \& Brosi, B. J. (2017). Fine scale population genetic structure of Varroa destructor, an ectoparasitic mite of the honey bee (Apis mellifera). Apidologie, 48(1), 93-101. https://doi.org/10.1007/s1359 2-016-0453-7

Ehrlich, P. R., \& Raven, P. H. (1964). Butterflies and plants: A study in coevolution. Evolution, 18(4), 586-608. https://doi.org/10.1111/ j.1558-5646.1964.tb01674.x

Eliash, N., \& Mikheyev, A. (2020). Varroa mite evolution: A neglected aspect of worldwide bee collapses? Current Opinion in Insect Science, 39, 21-26. https://doi.org/10.1016/j.cois.2019.11.004

European Commission (1992). Council Directive 92/65/EC. European Commission.

Evans, J. D. (2000). Microsatellite loci in the honey bee parasitic mite Varroa jacobsoni. Molecular Ecology, 9(9), 1436-1438. https://doi. org/10.1046/j.1365-294x.2000.00998-3.x

Excoffier, L., Smouse, P. E., \& Quattro, J. M. (1992). Analysis of molecular variance inferred from metric distances among DNA haplotypes: Application to human mitochondrial DNA restriction data. Genetics, 131, 479-491. https://doi.org/10.1093/genetics/131.2.479 
Freeland, J. R., Kirk, H., \& Petersen, S. (2011). Molecular ecology. Wiley Blackwell.

Frey, E., Schnell, H., \& Rosenkranz, P. (2011). Invasion of Varroa destructor mites into mite-free honey bee colonies under the controlled conditions of a military training area. Journal of Apicultural Research, 50(2), 138-144. https://doi.org/10.3896/IBRA.1.50.2.05

Fries, I. (1987). Diagnostik av kvalstret Varroa jacobsoni. Bitidningen, 86, 335-342.

Fries, I. (1991). Varroakvalstret, biologi \& diagnos. Lantbruksinformation.

Fries, I., \& Camazine, S. (2001). Implications of horizontal and vertical pathogen transmission for honey bee epidemiology. Apidologie, 32(3), 199-214. https://doi.org/10.1051/apido:2001122

Fries, I., Imdorf, A., \& Rosenkranz, P. (2006). Survival of mite infested (Varroa destructor) honey bee (Apis mellifera) colonies in a Nordic climate. Apidologie, 37(5), 564-570. https://doi.org/10.1051/apido :2006031

Gandon, S., \& Michalakis, Y. (2002). Local adaptation, evolutionary potential and host-parasite coevolution: Interactions between migration, mutation, population size and generation time. Journal of Evolutionary Biology, 15(3), 451-462. https://doi. org/10.1046/j.1420-9101.2002.00402.x

Gandon, S., \& Zandt, P. A. V. (1998). Local adaptation and host-parasite interactions. Trends in Ecology \& Evolution, 13(6), 214-216. https:// doi.org/10.1016/S0169-5347(98)01358-5

Georghiou, G. P. (1972). The evolution of resistance to pesticides. Annual Review of Ecology and Systematics, 3(1), 133-168. https://doi. org/10.1146/annurev.es.03.110172.001025

González-Cabrera, J., Bumann, H., Rodríguez-Vargas, S., Kennedy, P. J., Krieger, K., Altreuther, G., Hertel, A., Hertlein, G., Nauen, R., \& Williamson, M. S. (2018). A single mutation is driving resistance to pyrethroids in European populations of the parasitic mite, Varroa destructor. Journal of Pest Science, 91(3), 1137-1144. https://doi. org/10.1007/s10340-018-0968-y

Goudet, J. (1995). FSTAT (Version 1.2): A computer program to calculate F-statistics. Journal of Heredity, 86(6), 485-486. https://doi. org/10.1093/oxfordjournals.jhered.a111627

Gregorc, A., \& Planinc, I. (2001). Acaricidal effect of oxalic acid in honeybee (Apis mellifera) colonies. Apidologie, 32(4), 333-340. https://doi. org/10.1051/apido:2001133

Griffiths, D. A., \& Bowman, C. (1981). World distribution of the mite Varroa jacobsoni, a parasite of honeybees. Bee World, 62(4), 154-163.

Holm, S. (1979). A simple sequentially rejective multiple test procedure. Scandinavian Journal of Statistics, 6, 65-70.

Jaffé, R., Dietemann, V., Allsopp, M. H., Costa, C., Crewe, R. M., Dall'olio, R., De la rúa, P., El-niweiri, M. A. A., Fries, I., Kezic, N., Meusel, M. S., Paxton, R. J., Shaibi, T., Stolle, E., \& Moritz, R. F. (2010). Estimating the density of honeybee colonies across their natural range to fill the gap in pollinator decline censuses. Conservation Biology, 24(2), 583593. https://doi.org/10.1111/j.1523-1739.2009.01331.x

Jost, L. (2008). Gst and its relatives do not measure differentiation. Molecular Ecology, 17(18), 4015-4026. https://doi. org/10.1111/j.1365-294X.2008.03887.x

Kamler, M., Nesvorna, M., Stara, J., Erban, T., \& Hubert, J. (2016). Comparison of tau-fluvalinate, acrinathrin, and amitraz effects on susceptible and resistant populations of Varroa destructor in a vial test. Experimental and Applied Acarology, 69(1), 1-9. https://doi. org/10.1007/s10493-016-0023-8

Kamvar, Z. N., Tabima, J. F., \& Grünwald, N. J. (2014). Poppr: An R package for genetic analysis of populations with clonal, partially clonal, and/or sexual reproduction. PeerJ, 2, e281. https://doi.org/10.7717/ peerj.281

Kather, R., Drijfhout, F. P., Shemilt, S., \& Martin, S. J. (2015). Evidence for passive chemical camouflage in the parasitic mite Varroa destructor. Journal of Chemical Ecology, 41(2), 178-186. https://doi.org/10.1007/ s10886-015-0548-z
Koskella, B., \& Lively, C. M. (2009). Evidence for negative frequencydependent selection during experimental coevolution of a freshwater snail and a sterilizing trematode. Evolution, 63(9), 2213-2221. https://doi.org/10.1111/j.1558-5646.2009.00711.x

Kruitwagen, A., van Langevelde, F., van Dooremalen, C., \& Blacquière, T. (2017). Naturally selected honey bee (Apis mellifera) colonies resistant to Varroa destructor do not groom more intensively. Journal of Apicultural Research, 56(4), 354-365. https://doi.org/10.1080/00218 839.2017.1329797

Le Conte, Y., de Vaublanc, G., Crauser, D., Jeanne, F., Rousselle, J. C., \& Bécard, J. M. (2007). Honey bee colonies that have survived Varroa destructor. Apidologie, 38(6), 566-572. https://doi.org/10.1051/apido $: 2007040$

Le Conte, Y., Ellis, M., \& Ritter, W. (2010). Varroa mites and honey bee health: Can Varroa explain part of the colony losses? Apidologie, 41(3), 353-363. https://doi.org/10.1051/apido/2010017

Le Conte, Y., Huang, Z. Y., Roux, M., Zeng, Z. J., Christidès, J.-P., \& Bagnères, A.-G. (2015). Varroa destructor changes its cuticular hydrocarbons to mimic new hosts. Biology Letters, 11(6), 20150233. https://doi.org/10.1098/rsbl.2015.0233

Locke, B. (2016). Natural Varroa mite-surviving Apis mellifera honeybee populations. Apidologie, 47(3), 467-482. https://doi.org/10.1007/ s13592-015-0412-8

Locke, B., Conte, Y. L., Crauser, D., \& Fries, I. (2012). Host adaptations reduce the reproductive success of Varroa destructor in two distinct European honey bee populations. Ecology and Evolution, 2(6), 11441150. https://doi.org/10.1002/ece3.248

Maggi, M. D., Damiani, N., Brasesco, C., Szawarski, N., Mitton, G., Mariani, F., Sammataro, D., Quintana, S., \& Eguaras, M. (2017). The susceptibility of Varroa destructor against oxalic acid: A study case. Bulletin of Insectology, 70(1), 39-44.

Mantel, N. (1967). The detection of disease clustering and a Generalized Regression Approach. Cancer Research, 27(2), 209-220.

Martin, S. (1998). A population model for the ectoparasitic mite Varroa jacobsoni in honey bee (Apis mellifera) colonies. Ecological Modelling, 109(3), 267-281. https://doi.org/10.1016/S0304-3800(98)00059-3

Martin, S. J. (2004). Acaricide (pyrethroid) resistance in Varroa destructor. Bee World, 85(4), 67-69. https://doi.org/10.1080/00057 72X.2004.11099632

May, R. M., \& Anderson, R. M. (1990). Parasite-host coevolution. Parasitology, 100(S1), S89-S101. https://doi.org/10.1017/S0031 182000073042

Milani, N. (1999). The resistance of Varroa jacobsoni Oud. to acaricides. Apidologie, 30(2-3), 229-234. https://doi.org/10.1051/apido :19990211

Mondet, F., Beaurepaire, A., McAfee, A., Locke, B., Alaux, C., Blanchard, S., Danka, B., \& Le Conte, Y. (2020). Honey bee survival mechanisms against the parasite Varroa destructor: A systematic review of phenotypic and genomic research efforts. International Journal for Parasitology, 50(6-7), 433-447. https://doi.org/10.1016/j. ijpara.2020.03.005

Moritz, R. F. A., Kraus, F. B., Kryger, P., \& Crewe, R. M. (2007). The size of wild honeybee populations (Apis mellifera) and its implications for the conservation of honeybees. Journal of Insect Conservation, 11(4), 391-397. https://doi.org/10.1007/s10841-006-9054-5

Nanetti, A. (1999). Oxalic acid for mite control-Results and review. FAIR CT97-3686.

Navajas, M. J. (2010). Tracking the colonisation history of the invasive species Varroa destructor. In M. W. Sabelis, \& J. Bruin (Eds.), Trends in Acarology (pp. 375-378). Springer.

Neumann, P., \& Blacquière, T. (2017). The Darwin cure for apiculture? Natural selection and managed honeybee health. Evolutionary Applications, 10(3), 226-230. https://doi.org/10.1111/eva.12448

Neumann, P., \& Carreck, N. L. (2010). Honey bee colony losses. Journal of Apicultural Research, 49(1), 1-6. https://doi.org/10.3896/IBRA.1.49.1.01 
Nixon, M. (1983). World maps of Varroa jacobsoni and Tropilaelaps clareae, with additional records for honeybee diseases and parasites previously mapped. Bee World, 64, 124-131.

Oddie, M., Büchler, R., Dahle, B., Kovacic, M., Le Conte, Y., Locke, B., de Miranda, J. R., Mondet, F., \& Neumann, P. (2018). Rapid parallel evolution overcomes global honey bee parasite. Scientific Reports, 8(1), 7704. https://doi.org/10.1038/s41598-018-26001-7

Oddie, M., Dahle, B., \& Neumann, P. (2017). Norwegian honey bees surviving Varroa destructor mite infestations by means of natural selection. PeerJ, 5, e3956. https://doi.org/10.7717/peerj.3956

Oldroyd, B. P. (1999). Coevolution while you wait: Varroa jacobsoni, a new parasite of western honeybees. Trends in Ecology \& Evolution, 14(8), 312-315. https://doi.org/10.1016/S0169-5347(99)01613-4

Osakabe, M., Uesugi, R., \& Goka, K. (2009). Evolutionary aspects of Acaricide-resistance development in spider mites. Psyche: A Journal of Entomology, 2009, 1-11. https://doi.org/10.1155/2009/947439

Panziera, D., van Langevelde, F., \& Blacquière, T. (2017). Varroa sensitive hygiene contributes to naturally selected varroa resistance in honey bees. Journal of Apicultural Research, 56(5), 635-642. https://doi. org/10.1080/00218839.2017.1351860

Pascual-Ruiz, S., Gómez-Martinez, M. A., Ansaloni, T., Segarra-Moragues, J. G., Sabater-Muñoz, B., Jacas, J. A., \& Hurtado-Ruiz, M. A. (2014). Genetic structure of a phytophagous mite species affected by crop practices: The case of Tetranychus urticae in clementine mandarins. Experimental and Applied Acarology, 62(4), 477-498. https://doi. org/10.1007/s10493-013-9755-x

Paterson, S., Vogwill, T., Buckling, A., Benmayor, R., Spiers, A. J., Thomson, N. R., Quail, M., Smith, F., Walker, D., Libberton, B., Fenton, A., Hall, N., \& Brockhurst, M. A. (2010). Antagonistic coevolution accelerates molecular evolution. Nature, 464(7286), 275-278. https:// doi.org/10.1038/nature08798

Peakall, R., \& Smouse, P. E. (2012). GenAlEx 6.5: Genetic analysis in Excel. Population genetic software for teaching and researchdan update. Bioinformatics, 28, 2537-2539.

Potts, S. G., Biesmeijer, J. C., Kremen, C., Neumann, P., Schweiger, O., \& Kunin, W. E. (2010). Global pollinator declines: Trends, impacts and drivers. Trends in Ecology \& Evolution, 25(6), 345-353. https://doi. org/10.1016/j.tree.2010.01.007

Potts, S. G., Roberts, S. P. M., Dean, R., Marris, G., Brown, M. A., Jones, R., Neumann, P., \& Settele, J. (2010). Declines of managed honey bees and beekeepers in Europe. Journal of Apicultural Research, 49(1), 15-22. https://doi.org/10.3896/IBRA.1.49.1.02

R Core Team (2018). R: A language and environment for statistical computing. R Foundation for Statistical Computing. https://www.R-project.org/

Rath, W. (1999). Co-adaptation of Apis cerana Fabr. and Varroa jacobsoni Oud. Apidologie, 30(2-3), 97-110. https://doi.org/10.1051/apido :19990202

Rosenkranz, P., Aumeier, P., \& Ziegelmann, B. (2010). Biology and control of Varroa destructor. Journal of Invertebrate Pathology, 103, S96-S119. https://doi.org/10.1016/j.jip.2009.07.016

Ruttner, F., \& Ritter, W. (1980). The spread of Varroa jacobsoni into Europe-in retrospect. Allgemeine Deutsche Imkerzeitung, 14, 130-134.

Schmid-Hempel, P. (2011). Evolutionary parasitology: The integrated study of infections, immunology, ecology, and genetics. Oxford University Press.

Schulte, R. D., Makus, C., Hasert, B., Michiels, N. K., \& Schulenburg, H. (2010). Multiple reciprocal adaptations and rapid genetic change upon experimental coevolution of an animal host and its microbial parasite. Proceedings of the National Academy of Sciences of the United States of America, 107(16), 7359-7364. https://doi.org/10.1073/ pnas. 1003113107
Schulte, R. D., Makus, C., \& Schulenburg, H. (2013). Host-parasite coevolution favours parasite genetic diversity and horizontal gene transfer. Journal of Evolutionary Biology, 26(8), 1836-1840. https://doi. org/10.1111/jeb.12174

Seeley, T. D. (2007). Honey bees of the Arnot Forest: A population of feral colonies persisting with Varroa destructor in the northeastern United States. Apidologie, 38(1), 19-29. https://doi.org/10.1051/ apido: 2006055

Shannon, C., \& Weaver, W. (1949). The mathematical theory of communication. Illinois University Press.

Simpson, E. H. (1949). Measurement of diversity. Nature, 163(4148), 688-688.

Solignac, M., Cornuet, J., Vautrin, D., Le Conte, Y., Anderson, D., Evans, J., Cros-Arteil, S., \& Navajas, M. (2005). The invasive Korea and Japan types of Varroa destructor, ectoparasitic mites of the Western honeybee (Apis mellifera), are two partly isolated clones. Proceedings of the Royal Society B: Biological Sciences, 272(1561), 411-419. https://doi. org/10.1098/rspb.2004.2853

Spreafico, M., Eördegh, F. R., Bernardinelli, I., \& Colombo, M. (2001). First detection of strains of Varroa destructor resistant to coumaphos. Results of laboratory tests and field trials. Apidologie, 32(1), 49-55. https://doi.org/10.1051/apido:2001110

Szpiech, Z. A., Jakobsson, M., \& Rosenberg, N. A. (2008). ADZE: A rarefaction approach for counting alleles private to combinations of populations. Bioinformatics, 24(21), 2498-2504. https://doi.org/10.1093/ bioinformatics/btn478

Thompson, J. N. (2005). The geographic mosaic of coevolution. University of Chicago Press.

Traynor, K. S., Mondet, F., de Miranda, J. R., Techer, M., Kowallik, V., Oddie, M. A. Y., Chantawannakul, P., \& McAfee, A. (2020). Varroa destructor: A complex parasite, crippling honey bees worldwide. Trends in Parasitology, 36(7), 592-606. https://doi.org/10.1016/j.pt.2020.04.004

Uesugi, R., Kunimoto, Y., \& Osakabe, M. (2009). The fine-scale genetic structure of the two-spotted spider mite in a commercial greenhouse. Experimental and Applied Acarology, 47(2), 99-109. https://doi. org/10.1007/s10493-008-9201-7

Walsh, P. S., Metzger, D. A., \& Higuchi, R. (2013). Chelex 100 as a medium for simple extraction of DNA for PCR-based typing from forensic material. BioTechniques, 54(3), 506-513. https://doi.org/10.2144/000114018

Woolhouse, M. E. J., Webster, J. P., Domingo, E., Charlesworth, B., \& Levin, B. R. (2002). Biological and biomedical implications of the coevolution of pathogens and their hosts. Nature Genetics, 32(4), 569577. https://doi.org/10.1038/ng1202-569

\section{SUPPORTING INFORMATION}

Additional supporting information may be found online in the Supporting Information section.

How to cite this article: Moro A, Blacquière T, Dahle B, et al. Adaptive population structure shifts in invasive parasitic mites, Varroa destructor. Ecol Evol. 2021;11:5937-5949. https://doi. org/10.1002/ece3.7272 